\section{(2) OPEN ACCESS}

\title{
Being 'at-home' on outpatient parenteral antimicrobial therapy (OPAT): a qualitative study of parents' experiences of paediatric OPAT
}

\author{
Bernie Carter 이, ${ }^{1}$ Debra Fisher-Smith, ${ }^{2}$ David Porter, ${ }^{3}$ Steven Lane, ${ }^{4}$ Matthew Peak, ${ }^{5,6}$ \\ David Taylor-Robinson, ${ }^{7}$ Louise Bracken, ${ }^{8}$ Enitan Carrol ${ }^{9}$
}

\begin{abstract}
${ }^{1}$ Faculty of Health, Social
Care and Medicine, Edge Hill University, Ormskirk, UK ${ }^{2}$ Department of Clinical Infection, Microbiology and Immunology, University of Liverpool, Liverpool, UK ${ }^{3}$ Department of Infectious Diseases, Alder Hey Children's NHS Foundation Trust, Liverpool, UK

${ }^{4}$ Biostatistics, University of Liverpool, Liverpool, UK ${ }^{5}$ Research and Development, Alder Hey Children's NHS Foundation Trust, Liverpool, UK ${ }^{6}$ Cheshire and Merseyside Medicines for Children Research Network, Alder Hey Children's NHS Foundation Trust, Liverpool, UK

${ }^{7}$ Department of Public Health and Policy, University of Liverpool, Liverpool, UK ${ }^{8}$ Paediatric Medicines Research Unit, Alder Hey Children's NHS Foundation Trust, Liverpool, UK ${ }^{9}$ Department of Clinical Infection, Microbiology and Immunology, University of Liverpool, Liverpool, UK
\end{abstract}

\section{Correspondence to}

Professor Bernie Carter, Faculty of Health, Social Care and Medicine, Edge Hill University, Ormskirk L39 4QP, UK; bernie.carter@edgehill.ac.uk

Received 26 May 2019 Revised 8 August 2019 Accepted 5 September 2019 Published Online First 26 September 2019

\section{Check for updates}

(C) Author(s) (or their employer(s)) 2020. Re-use permitted under CC BY-NC. No commercial re-use. See rights and permissions. Published by BMJ.

To cite: Carter $B$, Fisher-

Smith D, Porter D, et al.

Arch Dis Child

2020;105:276-281.

\section{ABSTRACT}

Objective To better understand the factors that facilitate and hinder a positive experience of paediatric outpatient parenteral antimicrobial therapy (OPAT).

Design Qualitative study using semistructured interviews.

Setting A dedicated paediatric consultant-led hospitalbased, outreach OPAT service in England.

Participants Participants were primarily parents of children who had received OPAT; one child participated. Methods Children and parents of children who received OPAT and who had participated in the survey phase of the larger study were invited to be interviewed. Results 12 parents ( 10 mothers and 2 fathers) of 10 children participated; one child (aged 15 years). Data analysis resulted in one meta-theme, 'At-homeness' with OPAT, this reflected the overall sense of home being a place in which the children and their parents could be where they wanted to be. Four key themes were identified that reflect the ways in which parents and children experienced being at-home on OPAT: 'Comfort, security, freedom, and control'; 'Faith, trust and confidence'; 'Explanations and communication' and 'Concerns, restrictions and inconveniences'.

Conclusions Despite feeling anxious at times, parents reported that they and their children generally had a positive experience of OPAT; being at-home brought many benefits compared with in-patient care. Recommendations arising from the study include a 'whole-system' approach to discharge home that includes support related to return to school/nursery, reduction in disruptions to home-based routines, more clarity on choice and preparation for managing potential anxiety, better consideration of dose timing and enhanced preparation and information.

\section{INTRODUCTION}

Outpatient parenteral antimicrobial therapy (OPAT) for children is the parenteral administration of antimicrobials for at least two consecutive days without an intervening hospitalisation. ${ }^{1}$ Children with suspected serious bacterial infections ${ }^{2-6}$ but who are sufficiently stable and where other factors (eg, child's medical history) are taken into consideration may be appropriate for OPAT. Children are most commonly referred to OPAT after a period of hospitalisation, but in some cases directly from the emergency department. Although cure or improvement rates of $88 \%$ or above have been recorded for children receiving OPAT ${ }^{7-9}$ higher rates of adverse

\section{What is already known on this topic?}

- Children with suspected serious bacterial infections but who are sufficiently stable and where other factors are taken into consideration may be appropriate for outpatient parenteral antimicrobial therapy (OPAT).

- Reported benefits of paediatric OPAT include cost-effectiveness, and child/parent satisfaction and well-being but there is a lack of consensus about what constitutes success.

- Across adult and paediatric OPAT literature, patient experience is mostly limited to survey data and there is very limited robust qualitative evidence.

\section{What this study adds?}

Clear qualitative evidence about those factors which impact on the experience of parents whose children are receiving OPAT.

- The importance of accessible visual-based and text-based information and supportive clinical discussion to ensure adequate involvement of parents in the decision to opt for OPAT.

- The importance of tailoring dose timing to help streamline administration of medication within family routine.

events and readmission are reported in children than adults. ${ }^{10}$

Reported benefits of OPAT include costeffectiveness, ${ }^{11}$ and child/parent satisfaction and well-being. ${ }^{1}$ However, there is a lack of consensus about what constitutes success, the definition and reporting of adverse events, and the evidence base for the economic benefits of paediatric OPAT. ${ }^{12}$ Across all OPAT literature, patient experience is mostly limited to survey data; ${ }^{13}{ }^{14}$ the limited robust qualitative evidence in adults reveals that despite good clinical outcomes, some OPAT experiences can be troubled and challenging. ${ }^{15}$

This study, part of a larger mixed-methods study (in submission), aimed to better understand factors that facilitate and hinder a positive experience of paediatric OPAT. 


\section{MATERIALS AND METHODS}

\section{Study design and setting}

As part of a larger mixed-methods study, this exploratory, interpretivist qualitative study based on interpretive description ${ }^{16}$ was undertaken. The dedicated consultant-led, hospital-based, outreach OPAT service ${ }^{17}$ considers all referred children, without restriction on age or diagnosis, providing staff and child safety is not at risk. Qualified, trained children's community nurses visit once daily to administer medication, assess the child and provide support and advice; 24-hour telephone support is also available. Interviews were undertaken by a social scientist with experience in health research with children and no prior relationship with participants. Participants' responses to the survey were reviewed prior to their interview to allow the researcher insight into any particular factors that had been reported by the participant so that these could be explored in further depth.

\section{Participants and methods}

Parents of children ( $0-16$ years) and children (6 years or above) referred to the OPAT service at one UK-based tertiary children's setting and where parents had participated in the survey phase $(n=33)$ of the larger study were invited. Recruitment took place between November 2017 and August 2018. Face-to-face interviews were undertaken in the child's home, within 4 weeks of completion of OPAT care. Four questions elicited OPAT experiences related to sufficiency of information; effect on family life; worst/best things about OPAT and advice for other parents/ children.

Informed consent was gained from the parents for their own and their child's participation in the study, where appropriate. One child gave informed assent.

\section{Analysis}

All interviews were transcribed verbatim. Thematic analysis ${ }^{18}$ supported by an innovative serial-memoing step ${ }^{19}$ was undertaken. The usual key steps of thematic analysis of coding, developing and refining themes though immersion in the data occurred, and this was complemented by adding the additional perspectives of clinicians and parents to the analytical process by serial memoing. The parents were members of a service-user group based at the study hospital and the clinicians all had experience with the OPAT service. Both parents and clinicians were asked to read a transcript and then report their perspectives, responses and thoughts on a memoing-template; they were not aware of the researchers' initial themes. All of these responses were considered in relation to the initial themes developed through thematic analysis and these themes were refined and further developed until they were considered to be robust. BC and DF-S led on the analysis and synthesis of the data (figure 1).

\section{RESULTS}

In all, 12 parents (10 mothers and 2 fathers) of 10 children agreed to participate; one child (aged 15 years) was interviewed with her mother. The children (six boys and four girls) were aged between 5 weeks and 15 years. Children had been in hospital and receiving antibiotics from 1 to 21 days. The duration of OPAT ranged from 1 to 21 days (mean 8.3 days); the one child who did not meet the OPAT definition of 2 days home-based treatment was included as they had come close to 48 hours of home-based care. Reasons for OPAT varied; four children did not have an associated disorder (table 1). Three children had previous experience of OPAT.

The main theme, 'At-homeness' with OPAT, reflected the overall sense of home being a place in which the children and their parents could be where they wanted to be and was supported by four subthemes (figure 2). The following abbreviations are used with quotations: M (mother); F (father); C (child).

\section{Comfort, security, freedom and control: the normality of being at-home}

Despite gratitude for the hospital-based care, parents were mostly 'desperate' to go home, regardless of length of stay; they were 'exhausted' and in 'survival mode'. Hospital imposed its routines, bureaucracy and costs on parents and while acceptable when their child was ill, they became more difficult to accept as their child's condition improved. The pull of home was strong; not least because hospitalisation often resulted in family separation.

Treatment at home was mostly reported as generating a sense of comfort and security and a chance to heal, recuperate and 'get

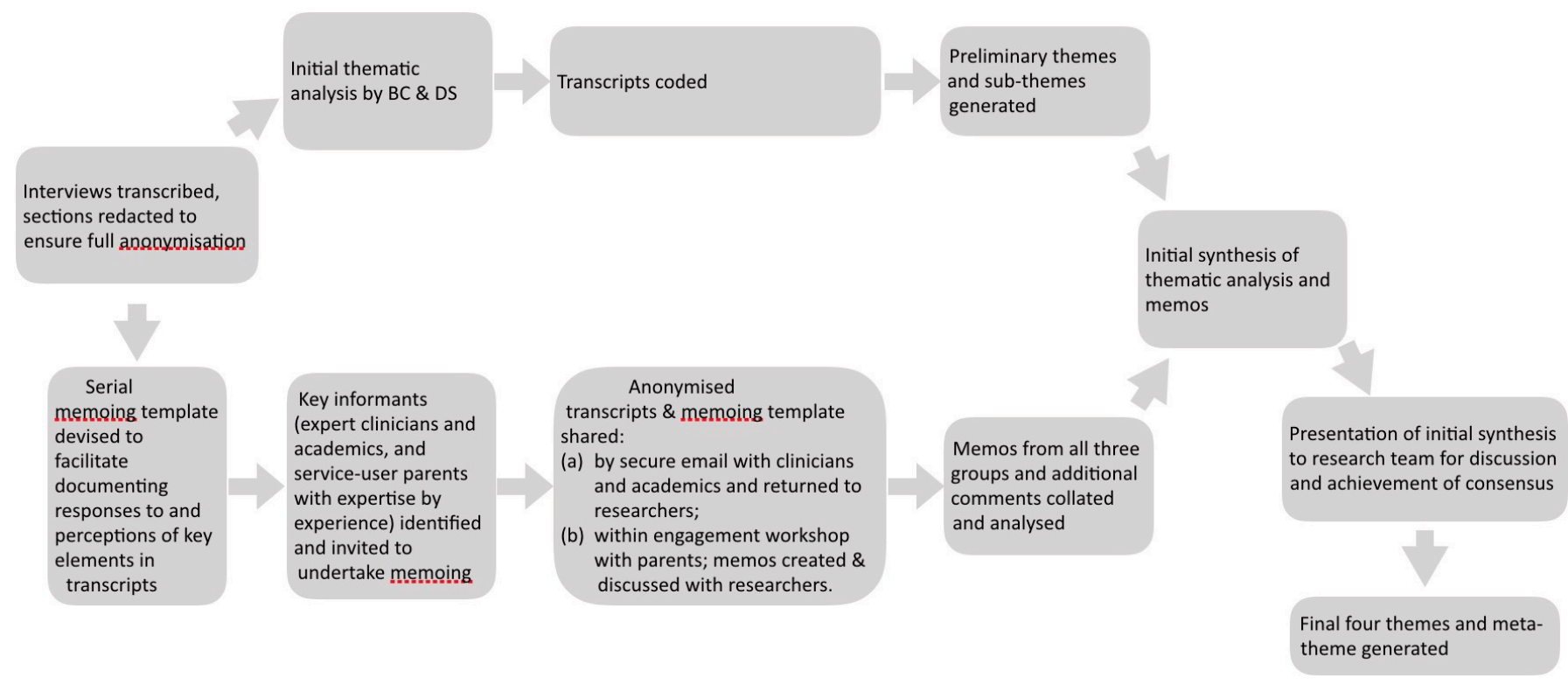

Figure 1 Overview of analytical process: thematic analysis, serial memoing and synthesis. 


\begin{tabular}{|c|c|c|c|c|c|c|c|c|c|c|}
\hline ID number & 1 & 2 & 3 & 4 & 5 & 6 & 7 & 8 & 9 & 10 \\
\hline Participants & $\begin{array}{l}\text { Mother, } \\
\text { child }\end{array}$ & Mother & $\begin{array}{l}\text { Mother, } \\
\text { father }\end{array}$ & Mother & $\begin{array}{l}\text { Mother, } \\
\text { father }\end{array}$ & Mother & Mother & Mother & Mother & Mother \\
\hline Child's gender & $\mathrm{F}$ & $\mathrm{F}$ & $\mathrm{M}$ & M & M & M & $\mathrm{F}$ & M & $\mathrm{F}$ & M \\
\hline Child's age & 15 years & 4 years & 6 months & 6 years & 4 years & 7 years & 3 years & 8 years & 4 years & 5 weeks \\
\hline Reason for OPAT & $\begin{array}{l}\text { Perforated } \\
\text { appendix }\end{array}$ & $\begin{array}{l}\text { Chest } \\
\text { infection }\end{array}$ & Sepsis & Pneumonia & Meningitis & $\begin{array}{l}\text { Occular } \\
\text { cellulitis }\end{array}$ & $\begin{array}{l}\text { Chest } \\
\text { infection }\end{array}$ & $\begin{array}{l}\text { Occular } \\
\text { cellulitis }\end{array}$ & Pneumonia & $\begin{array}{l}\text { E.Coli } \\
\text { septicaemia }\end{array}$ \\
\hline Days on OPAT & 7 & 21 & 1 & 3 & 4 & 2 & 14 & 14 & 7 & 10 \\
\hline $\begin{array}{l}\text { Prior OPAT } \\
\text { experience }\end{array}$ & No & Yes & No & Yes & No & No & Yes & No & No & No \\
\hline
\end{tabular}

ALL, acute lymphoblastic leukaemia; CHCN, complex healthcare needs; OPAT, outpatient parenteral antimicrobial therapy.

back to normality' (M4). Home was a place parents felt created the best conditions for their child to:

recuperate better, be comfy......less bugs, less infections, easier for the family (M2).

Being home also supported the parent's recovery from the stress of the child's illness; 'we could both relax then' (M10). Alongside the sense of ease and comfort engendered by being at-home, parents regained control over the small, cumulative aspects of family life (eg, food choices, bed times, reliance on others). The normality of home was prized despite it being temporarily reshaped by the 'mild inconvenience' (M9) of being available for the child's daily antimicrobials. However, one girl aged 15 years 'didn't feel safe' and her mother struggled to find a sense of security at home; they missed the reassuring presence of 'medical professionals around you' (M1).

Faith, trust and confidence: the conditions for being happy with OPAT

Overall, parents were 'happy' with the choice they had made about OPAT, acknowledging they had been 'led by the doctors... they knew best' (M4). Despite one parent feeling 'a bit like they wanted us to go home' (M1), the other parents did not feel pressured:

...if I'd said 'No. I've got worries' they'd have kept him in no problem (M4).

Parents had implicit 'faith in the medical professionals' (M46); this trust and confidence were engendered and sustained by the technical competence and emotional literacy of the health professionals at each step of the OPAT journey. The OPAT nurses were praised for 'being extremely good' (M6) and for their organisation, timeliness, follow-up, engagement and technical ability. Knowing that the hospital was there 'if needed', supported a general sense of satisfaction that 'all was well'.

\section{Explanations and communication: the information sharing and support}

Good, reciprocal communication between the hospital and the community both prior to discharge and once at home supported continuity of care and underpinned and sustained parents' confidence. The nurses provided the children with 'nice' (M5) explanations about what they were doing. Most communication was information based, explaining what would happen and was fairly specifically focused on intravenous access, preserving access and keeping their child safe. Explanations were generally good as both hospital-based and home-based staff 'explained everything' (F3) and were as 'clear as day' (M6). However, most parents had little recall of being given information about possible adverse events. Some parents talked of being 'so focused on caring' or 'too tired' to concentrate, that they did not 'glance' (M1) at the paperwork until their child had completed OPAT. Information went:

in one ear and out the other to be completely honest...we were tired...absolutely exhausted (M9).

As needed, parents took on the responsibility for informing other key people in the child's life such as teachers, nursery workers, and club leaders.

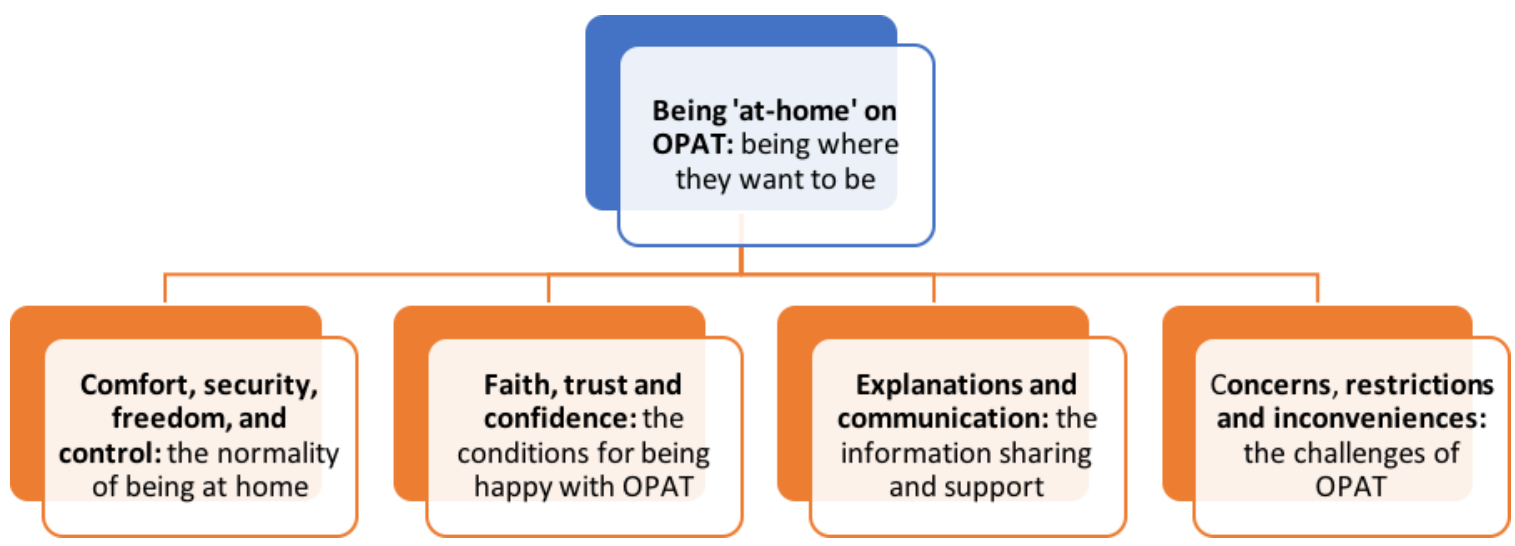

Figure 2 Overview of meta-theme and key themes. 


\section{Concerns, restrictions and inconveniences: the challenges of OPAT}

During the initial period of acute illness, all of the parents were stressed and anxious but as their child was recovering, most parents' stress levels reduced. Most home-based concerns were perceived as being minor and manageable. However, one parent remained anxious, recalling that OPAT was 'a scary experience' (M1) and another parent said, 'it was like you're home now, you deal with it' (F5).

Most concerns were line related such as air getting into the line or their child 'knocking' (M48) or displacing their catheter ('longline')/cannula and the line 'failing' (M10). Some parents were concerned about their child going to nursery/school and were adamant they would not 'send her into school with that line in her arm' (M9). While some settings were 'brilliant' and engaged effectively with parents, others imposed restrictions (eg, no outside play) or would 'accept no responsibility' (M7) which limited the ease of the child's return to school or nursery. Despite some parents restricting their child's adventurous play to avoid the perceived 'quite nasty' (M8) outcomes of a displaced line, others took a very pragmatic attitude to the longline, with one mother noting that her daughter was soon:

doing handstands and cartwheels... I thought she's got to live her life... she can't not be her (M7).

Few concerns were raised about the possible adverse effects associated with the antimicrobial drugs being administered, although one child who felt 'really drowsy all the time' (C1) explained she did not know about what side effects to expect. One mother who said that no one had 'explained any specific side effects' talked of her anxiety after reading about the side effects:

\section{I really rather wish I hadn't because...they get quite scary if you carry on reading (M9).}

Some inconveniences were reported, these included the amount of space taken up by the 'big boxes' and concerns about cleanliness in relation to making up medicines:

I had to Dettol the kitchen surfaces, like 50 thousand times because I was just worried (M4).

However, the main inconvenience related to the timing of the treatment which although 'not a big issue' could make you 'feel like your day has been robbed' (F3). All of the parents understood that their 'slot' for treatment was based on the due-time of their child's treatment but life was described as 'a bit tricky' for those whose treatment coincided with school drop-off or pick-up times. Parents also talked about being able to negotiate a slightly later timing if they were running late.

\section{DISCUSSION}

The growing evidence about the clinical outcomes of OPAT for children ${ }^{2} 510$ has overlooked the perspectives and experiences of children and their parents ${ }^{12}$ and a mix of methodological issues and the age of the studies limits the utility of this evidence to current practice. The suggested standardised survey for routinely collecting patient/parent satisfaction ${ }^{1}$ is unlikely to generate the range and depth of experience that will illuminate practice. While material and personal circumstances have been shown to be influential for adult patients, ${ }^{15}$ this was not evident in our findings. Previous research reports parental reluctance to go home,${ }^{20}$ this was not the case in this study. All parents, even those of the youngest children who anecdotally are perceived as being more reluctant to accept OPAT, trusted the judgement of the OPAT clinicians. Although this study revealed an initial acceptance of OPAT, like other studies, a few parents expressed reluctance to consider OPAT, if offered, again, ${ }^{21}$ noting they had felt 'a bit let down', 'alone' or 'stressed'. This could potentially be overcome by enhanced information and support.

Parents talked of comfort, security, recuperation, normality and control when describing the benefits of being 'at-home' with their child. These benefits tended to outweigh any of the challenges they experienced related to their child's OPAT, as seen in other studies reporting positive experiences. ${ }^{313}$ Parents' descriptions resonate with Seamon's ${ }^{22}$ classic work on 'at-homeness' and explain why, despite the hospital being perceived as the right place for a sick child, it was equally perceived as a place that could not easily meet the needs of a recovering child and their family. 'At-homeness' is comprised of rootedness, appropriation, regeneration, at-easeness and warmth. ${ }^{22}$ Each aspect was talked about by the parents either in terms of the disruption they experienced during the child's period of hospitalisation or the way in which this disruption settled when their child was home. Even the mother and child who would have preferred to have stayed in hospital because it felt safer, acknowledged they would have longed to be at home.

'Rootedness' ${ }^{22}$ reflects the sense of security about a place-in this case the child's home-that reflects the taken-for-granted and unselfconscious 'time-space routines' that people engage in as a natural part of their daily lives. While the child was in the hospital, their life and their accompanying parent's life were disrupted by the imposition of hospital routines; this disruption was experienced regardless of length of stay. The desire to go home, was in part a desire to be part of the familiar routines of home. For the most part, OPAT allowed the family to sink back into familiar routines and regain a sense of integrity and 'normality'. 'Coupling constraints' (times when the nurses and the parent/child needed to be in the same place $)^{23}$ created some 'minor inconveniences' rather than the 'wild' disruptions associated with in-patient care, as seen with some adult services. ${ }^{15}$ Other home-based services for children reveal similar reductions in stress and disruption to daily family life. ${ }^{24}$ However, it is clear that further reducing disruptions to family routines would be welcomed by parents if this could be clinically accommodated.

'Appropriation' is the sense that people are in control over the space they are in. ${ }^{22}$ Despite receiving good care within the hospital, the parents talked of home as being a place where they could feel comfortable, more independent and private, and more able to regain their role as a decision-making parent. Although some parents felt sufficiently confident to let their child go to nursery or school, others decided to keep their children at home as it avoided external dangers. Some settings (schools/nurseries) considered children receiving OPAT to be too risky and created barriers to the children returning to their usual routine. This is perhaps unsurprising considering the reluctance noted by some schools to rise to the challenge of managing medicines within school $^{25}$ - even though medicines were never administered at school. More liaison with schools and nurseries by clinicians could improve the chances of children being able to gain the most from being on OPAT.

'Regeneration' reflects the home as being a place of restoration and shelter where people can restore their emotional and physical sense of self. ${ }^{22}$ The parents talked of home as being the best place for their child to heal and recuperate as they would be able to sleep in their own bed and play with their own toys. This regeneration was less likely to happen in hospital which is more stressful, ${ }^{26}$ less comfortable and familiar. Arguably, being 
able to return to school/nursery when well enough would also be supportive of children being restored to their usual sense of self.

'At-easeness' 22 was a relief after the routines and processes associated with in-patient care. Simply put, at-easeness is about being able to be yourself rather than having to project a particular 'face'; being on familiar territory meant that parents could relax. However, for some parents, the first home visit disrupted this at-easeness as it was a reminder within their home of the hospital and the treatment. Some parents also reported feeling insecure at the start of home-based treatment, ${ }^{27}$ although this settled as they became accustomed to OPAT and this was helped by supportive relationships with OPAT nurses. Improving the preparation of parents for the practicalities of OPAT and the information about adverse events and guidance about any restrictions to play for a child with a line in situ is likely to be beneficial. Although some parents had read the written information others had been too tired or overwhelmed although they felt able to ask questions as needed. Studies that have considered discharge teaching and information suggest that nurse teaching skills and other factors such as the quality of teaching and parent-readiness for discharge ${ }^{28}$ are important. Findings from a systematic review reveal that parents have difficulty managing discharge instructions. ${ }^{29}$

The sense of 'warmth"22 was experienced by parents and children as a result of being encompassed within a strong set of supportive family relationships.

Our study is limited by the fact the sample size was small and diverse in terms of age and experience meaning our dataset was too small to undertake comparison of experience in relation to age of child, diagnosis, length of hospital stay or other factors.

Recommendations arising from the study include better information, more clarity on choice and preparation for managing potential anxiety, and better consideration of dose timing (box 1).

\section{CONCLUSIONS}

Despite the challenges inherent in OPAT, being at-home was perceived by most of the parents to be the best place for treatment, in terms of comfort and recuperation. Improvements to preparation and information about OPAT, the medicines and negotiation of treatment times are important ways

\section{Box 1 Key recommendations to support parents}

1. Improved information sheets for parents about OPAT, developed with parents to provide key information in a very accessible form (eg, visual rather than solely text based) and clearer emphasis on parental choice about OPAT.

2. Clearer emphasis within information sheets and clinical discussion about OPAT being predicated on parental choice and option to decline.

3. Clearer recognition within information sheets and clinical discussion that parents and child may feel anxious about OPAT until they have settled into the routine.

4. Clearer direction for parents to standardised and parentfriendly information about OPAT drugs (eg, through extension of content of medicinesforchildren.org.uk).

5. More tailored dose timing to help streamline administration of medication within family routine.

6. Information sheets for parents to be able to give to teachers, nursery staff, etc to help them understand OPAT and the implications for their staff/organisation. of improving the experience of parents and children being at-home on OPAT. Adopting an improved 'whole-system' approach focusing on the child being able to live a full life on OPAT would be beneficial.

Acknowledgements We would like to thank the parents and children who participated in the study and the parents and clinicians who contributed to developing our insights at the data analysis stage.

Contributors EDC, BC DT-R, DP, SL, LB and MP designed the study and applied for funding. DP and DF-S recruited patients and collected data. BC wrote the first draft of the manuscript. All authors contributed to drafting the manuscript.

Funding This work was supported by the National Institute for Health Research Collaboration for Leadership in Applied Health Research and Care North West Coast (NIHR CLAHRC NWC): study reference CLAHRC-NWC-034. The views expressed are those of the authors and not necessarily those of the NHS, NIHR or Department of Health and Social Care

Competing interests None declared.

Patient consent for publication Obtained.

Ethics approval Ethics approval was gained (NW Greater Manchester West Research Ethics Committee 16/NW/0440).

Provenance and peer review Not commissioned; externally peer reviewed. Data availability statement Data are available upon reasonable request.

Open access This is an open access article distributed in accordance with the Creative Commons Attribution Non Commercial (CC BY-NC 4.0) license, which permits others to distribute, remix, adapt, build upon this work non-commercially, and license their derivative works on different terms, provided the original work is properly cited, appropriate credit is given, any changes made indicated, and the use is non-commercial. See: http://creativecommons.org/licenses/by-nc/4.0/.

\section{ORCID iD}

Bernie Carter http://orcid.org/0000-0001-5226-9878

\section{REFERENCES}

1 Patel S, Abrahamson E, Goldring S, et al. Good practice recommendations for paediatric outpatient parenteral antibiotic therapy (p-OPAT) in the UK: a consensus statement. J Antimicrob Chemother 2015;70:360-73.

2 Krah NM, Olson J, Thorell EA, et al. Outpatient parenteral antimicrobial therapy in young infants. J Pediatric Infect Dis Soc 2018;7:e40-2.

3 Wiernikowski JT, Rothney M, Dawson S, et al. Evaluation of a home intravenous antibiotic program in pediatric oncology. J Pediatr Hematol Oncol 1991;13:144-7.

4 Maraqa NF, Gomez MM, Rathore MH. Outpatient parenteral antimicrobial therapy in osteoarticular infections in children. J Pediatr Orthop 2002;22:506-10.

5 Mace AO, McLeod C, Yeoh DK, et al. Dedicated paediatric outpatient parenteral antimicrobial therapy medical support: a pre-post observational study. Arch Dis Child 2018;103:165-9.

6 Glackin L, Flanagan F, Healy F, et al. Outpatient parenteral antimicrobial therapy: a report of three years experience. Ir Med J 2014;107:110-2.

7 Madigan T, Banerjee R. Characteristics and outcomes of outpatient parenteral antimicrobial therapy at an academic children's hospital. Pediatr Infect Dis J 2013;32:346-9.

8 Le J, San Agustin M, Hernandez EA, et al. Complications associated with outpatient parenteral antibiotic therapy in children. Clin Pediatr 2010;49:1038-43.

9 Gomez M, Maraqa N, Alvarez A, et al. Complications of outpatient parenteral antibiotic therapy in childhood. Pediatr Infect Dis J 2001;20:541-3.

10 Sriskandarajah S, Hobbs J, Roughead E, et al. Safety and effectiveness of 'hospital in the home' and 'outpatient parenteral antimicrobial therapy' in different age groups: a systematic review of observational studies. Int J Clin Pract 2018;72:e13216.

11 Van Winkle P, Whiffen T, Liu I-LA. Experience using peripherally inserted central venous catheters for outpatient parenteral antibiotic therapy in children at a community hospital. Pediatr Infect Dis J 2008;27:1069-72.

12 Carter B, Carrol ED, Porter D, et al. Delivery, setting and outcomes of paediatric Outpatient Parenteral Antimicrobial Therapy (OPAT): a scoping review. BMJ Open 2018;8:e021603

13 Bolsover S. Introducing outpatient parenteral antimicrobial therapy in a children's Hospital. Nurs Child Young People 2018;30:24-7

14 Orme LM, Babl FE, Barnes C, et al. Outpatient versus inpatient IV antibiotic management for pediatric oncology patients with low risk febrile neutropenia: a randomised trial. Pediatr Blood Cancer 2014;61:1427-33.

15 Twiddy M, Czoski Murray CJ, Mason SJ, et al. A qualitative study of patients' feedback about Outpatient Parenteral Antimicrobial therapy (OPAT) services in Northern England: implications for service improvement. BMJ Open 2018;8:e019099.

16 Thorne S. Interpretive description. Walnut Creek, California: Left Coast Press, 2016. 
17 Crouch C, Sharpe D, Porter D, et al. P34 Successful introduction of an outpatient parenteral antimicrobial therapy (opat) programme in a large uk paediatric hospital. Arch Dis Child 2018;103:e2

18 Braun V, Clarke V. Using thematic analysis in psychology. Qual Res Psychol 2006;3:77-101.

19 Patel K, Auton MF, Carter B, et al. Parallel-Serial Memoing: a novel approach to analyzing qualitative data. Qual Health Res 2016;26:1745-52.

20 Gauthier M, Chevalier I, Sterescu A, et al. Treatment of urinary tract infections among febrile young children with daily intravenous antibiotic therapy at a day treatment center. Pediatrics 2004;114:e469-76.

21 van der Laag J, van de Weg L. Cystic fibrosis and outpatient treatment with parenteral antibiotics in children. Int J Antimicrob Agents 1995;5:63-5.

22 Seamon D. A geography of the lifeworld : movement, rest and encounter. London: Croom Helm, 1979.

23 Schwanen T. On 'arriving on time', but what is 'on time'? Geoforum 2006;37:882-94.
24 Lippert M, Semmens S, Tacey L, et al. The hospital at home program: no place like home. Curr Oncol 2017;24:23-7.

25 Bellis JR, Arnott J, Barker C, et al. Medicines in schools: a cross-sectional survey of children, parents, teachers and health professionals. BMJ Paediatr Open 2017; 1:e000110.

26 Jones CW, Lynn MR. Blogs written by families during their child's hospitalization: a thematic narrative analysis. J Pediatr Nurs 2018;41:110-6.

27 Shemesh E, Yaniv I, Drucker M, et al. Home intravenous antibiotic treatment for febrile episodes in immune-compromised pediatric patients. Med Pediatr Oncol 1998;30:95-100

28 Weiss ME, Sawin KJ, Gralton K, et al. Discharge teaching, readiness for discharge, and post-discharge outcomes in parents of hospitalized children. J Pediatr Nurs 2017;34:58-64.

29 Glick AF, Farkas JS, Nicholson J, et al. Parental management of discharge instructions: a systematic review. Pediatrics 2017;140:e20164165. 